\title{
Consumption function and price elasticity of tobacco demand in Nigeria
}

\author{
Folashayo Adeniji'
}

\begin{abstract}
INTRODUCTION Tobacco consumption remains a major threat to population and public health globally. In response, an increase in the taxes levied on tobacco products has been found to be an effective intervention for controlling their use. In Nigeria, studies assessing the impact of excise taxes on tobacco use are less advanced. As such, this study evaluated the consumption function and price elasticity of tobacco demand in Nigeria.

METHODS This study used cross-section data from the Harmonized Nigerian Living Standard Survey (HNLSS, 2009-2010). Quadratic Almost Demand System (QUAIDS) of tobacco budget share and unit value equations were specified. Within and between cluster variation in prices and quantities demanded were used to determine the price elasticity of tobacco demand.

RESULTS Household size, food price index, level of education/literacy of household head and income were significant determinants of tobacco consumption. Also, rural and urban price elasticities of tobacco demand were -0.63 and -0.49 while the national price elasticity of tobacco demand was -0.62 .

ConcLusions The results of this study show that for every $5 \%$ increase in the price of tobacco, there will be a corresponding reduction of about $3 \%$ in the quantity of tobacco demanded in the national and rural samples. While the same increase in the price of tobacco products will generate about $2 \%$ reduction in quantity of tobacco consumed in urban settings in Nigeria. This finding is consistent with earlier studies in low-and-middle income countries.
\end{abstract}

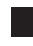

\section{AFFILIATION \\ 1 Department of Health Policy \& Management, Faculty of Public Health, College of Medicine, University of Ibadan, Ibadan, Nigeria}

CORRESPONDENCE TO Folashayo Adeniji. Department of Health Policy \& Management, Faculty of Public Health, College of Medicine, University of Ibadan, Ibadan, Nigeria. E-mail: folashayoadeniji@yahoo.co.uk

\section{KEYWORDS}

smoking, tobacco control, tobacco use, price elasticity, health, Nigeria

Received: 23 August 2019 Revised: 5 November 2019

Accepted: 7 November 2019

\section{INTRODUCTION}

An overwhelming body of research has linked tobacco consumption to numerous disease conditions ${ }^{1-3}$. It is a major risk factor for cancers, emphysema, chronic obstructive pulmonary diseases and the leading cause of avoidable diseases ${ }^{4-6}$. Also, the occurrences of miscarriages, premature births, low birth weight, sudden infant deaths syndrome and erectile dysfunction have been found to increase with tobacco use ${ }^{7-11}$. Smoking presents an extremely high risk of premature death compared to other modifiable health risk behaviours. It is expected that more than $50 \%$ of long-term smokers will likely eventually die in their productive middle-age as a result of the health consequences of the chemicals in tobacco ${ }^{12}$. In 2010 alone, there were about 5.7 million tobacco related deaths, globally ${ }^{13}$. Although, the prevalence of tobacco use has decreased in developed countries, this decline has been compensated by an increase in lowand-middle-income countries (LMIC). Of the over 1.1 billion current smokers globally in 2019 , about 880 million live in developing countries ${ }^{14}$. Despite the already enormous double burden of communicable and non-communicable diseases in LMICs, these countries face an increased risk of higher burden of tobacco-related health conditions in the future. A study projected that a disproportionate 6.8 million out of 8.3 million global deaths are likely to occur in 
LMICs by $2030^{15}$.

United Nations data on global consumption revealed that about 1.79 billion $\mathrm{N}$ (Nigerian Naira, about 11.9 million US\$) were spent on tobacco consumption in Nigeria in 2010 alone ${ }^{16}$. More so, adult smoking was reported to be $9 \%$, with $9.7 \%$ for teenage boys and $5.7 \%$ for teenage girls in Nigeria in $2010^{17}$. Likewise, the World Health Organization (WHO) estimated tobacco use in men and women in Nigeria at $10 \%$ and $2 \%$, respectively, in $2011^{18}$. Worse still, adult smoking rose to $13.7 \%$ of the total population in $2015^{17}$.

To control the use of tobacco products, WHO through its Framework Convention on Tobacco Control (FCTC) recommended a set of 'best buys' policy interventions. These measures include the use of the economic tool, i.e. regular increase excise taxes on tobacco products, as well as a wide range of legislative measures (imposition of large graphical health warnings on all tobacco packages; enforcement of comprehensive ban on all forms of tobacco advertising, promotions and sponsorship; restriction of smoking in indoor work and public places, and on public transport etc. $)^{19-21}$.

Studies have shown that raising the price of tobacco products presents a huge potential for reducing the prevalence and incidence of tobacco use globally. The extent of this impact is often captured using price elasticity of tobacco demand. Although, the reported price elasticity of tobacco demand in the literature varies, there is consensus regarding the range. For instance, Czubek and $\mathrm{Johal}^{22}$, calibrated a number of models estimating the price elasticity of duty-paid cigarettes in the United Kingdom and reported that the degree of responsiveness of tobacco demand to increases in tobacco taxes ranged between -0.17 and -0.92 . Also, a number of other studies ${ }^{23-29}$ conducted reported values between -0.15 and -0.72 . Gibson and $\mathrm{Kim}^{30}$ estimated the price elasticity of tobacco products with a focus on quantity and quality margins. Their study suggests that price elasticity of quality represents about two-thirds (-0.67) of the overall response due to quality shading, whereas one-third (-0.33) was accounted by price elasticity of quantity, particularly when analyzing household survey and when unit value is used as proxy for price $^{30}$. Generally, socioeconomic status has been found to be a major determinant of how strongly smokers respond to price increases, as poorer smokers are more responsive to price changes compared with economically viable smokers ${ }^{26,31}$.

\section{Tobacco use and trade in Nigeria}

According to the Global Adult Tobacco Survey (GATS) conducted in 2012 in Nigeria, the level of tobacco consumption was the highest in the Southeast region $(9.1 \%)$ and the lowest in the Northwest region $(2.7 \%)$ of the country. The prevalence for the entire country was $5.6 \%$, which represents about 9.21 million users of tobacco products in 2012. Given that GATS 2012 is the latest survey of the level of tobacco use in Nigeria, it is unclear whether the prevalence of tobacco use has progressed or decreased as at 2019. However, some reports have shown that given the level of efforts to control tobacco use in Nigeria, the level of its use might keep increasing with the population level ${ }^{18}$.

Exposure to secondhand smoke is regarded as passive/involuntary smoking and as such can be seen as a form of tobacco use (and also constitutes negative externality). The GATS survey revealed that the proportion of individuals exposed to secondhand smoke (mainly in restaurants and some public places) in the Southeast region of Nigeria was $50.3 \%$ in 2012 . The level of exposure in NorthCentral Nigeria was $27.8 \%$ while this was about the same for Northeast and Northwest (27.5\%). Exposure to secondhand smoke nationally was slightly higher at $29.3 \%$ (this represents about 6.4 million adults that were exposed to secondhand smoke during the period under review). Given the reported health effects posed by exposure to secondhand smoke to population and public health, these statistics reaffirm that the threat posed by tobacco use may be rising in the country.

In the GATS, average monthly expenditure on manufactured cigarettes was elicited and revealed that smokers in North-Central and South-South spent more ( $\$ 3791.9$ and $\$ 2540.8$, respectively) on the average compared with smokers in the other regions of the country. The average monthly expenditure on manufactured cigarettes was lower in the Northeast ( $\$ 1274.5$ ) compared with that of a typical smoker in the Southeast ( $\$ 1806.3$ ). National estimates show that smokers spent N1202.5 on manufactured cigarettes in 2012. The 
differentials in the average monetary outlay by smokers on manufactured cigarettes can be a result of differentials in the price of various brands across regions in the country. Also, some smokers might be smoking higher quality brands that usually have higher prices.

Figure 1 shows exports and imports of all tobacco products: cigarettes (of tobacco or of tobacco substitutes), cigars, cigarillos, and unmanufactured tobacco, tobacco refuse) from 2010-2017 ${ }^{32}$. The value of exports surpassed that of imports of all tobacco products between 2010 and 2012. The trend changed from 2013-2015 when negative net export was experienced. This was the highest in 2013 as import value surged above export by 1.269 billion US\$ (the highest within the period under review). In 2016, a positive net export was attained by the Nigerian tobacco industry, but the situation

Figure 1. Tobacco exports and imports in Nigeria, all products (2010-2017)

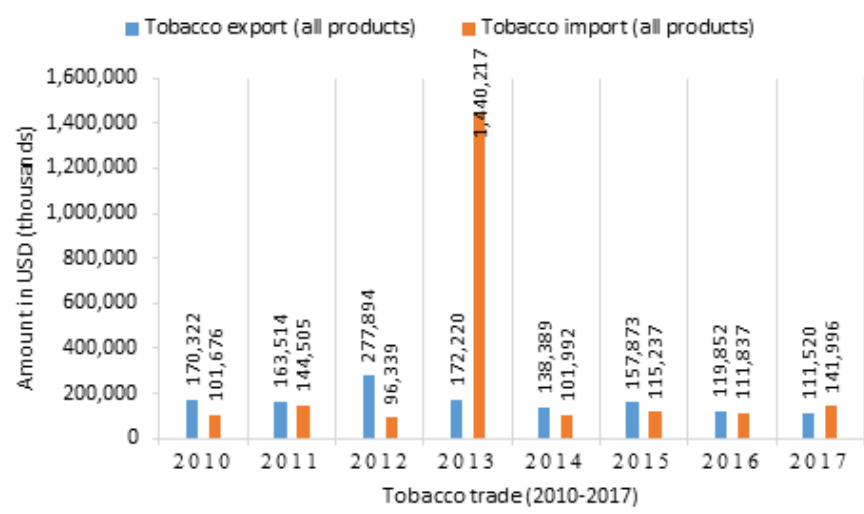

Source: UN COMTRADE database (2019)

Figure 2. Trend in net export of all tobacco products (2010-2017)

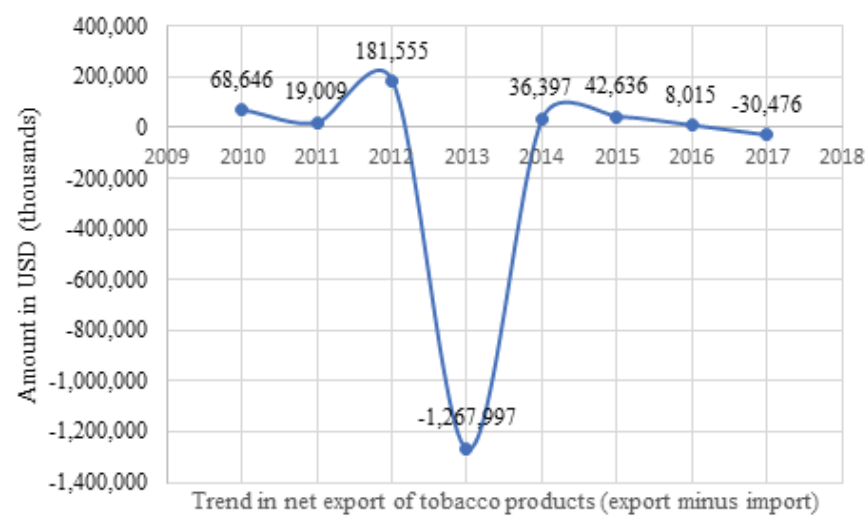

Source: UN COMTRADE database (2019) reversed again in 2017. The movement in net export of all tobacco products in Nigeria from 2010-2017 is depicted in Figure 2. This trend is typical of a business cycle (also called economic or trade cycle) with upward (peaks) and downward movements (troughs). As shown in Figure 2, the period between 2012 and 2014 had a bell-like shape, representing an enormous negative export (with a difference of -1.27 billion US\$). In general, this trend was fairly stable after 2014. There was a positive net export prior to 2013 and the volume of export recovered in 2014 before falling again in 2017 .

Nigeria ratified the WHO FCTC in 2005, however, studies that assessed the impact of excise tax on tobacco products are few. Meanwhile, research has shown that increases in excise taxes remains the most effective tool for tobacco control ${ }^{22-24}$. In general, optimal taxation of tobacco products represents vital input in the formulation of tobacco control policies globally, as proposed in the WHO FCTC through the MPOWER measures.

As such, this study estimates the consumption function and price elasticity of tobacco demand in Nigeria. This is with the aim that findings from the study will provide further evidence for developing optimal tobacco excise taxation in Nigeria.

\section{METHODS}

Data

The data for this study were drawn from the Harmonised Nigerian Living Standard Survey (HNLSS) conducted in 2009-2010 by the National Bureau of Statistics (NBS). The HNLSS survey collected broad information on demographics, health and fertility behavior, education and skill training, employment and time-use, household income, consumption and expenditure on a broad category of commodities including tobacco products (NBS, 2012). This survey adopted the Enumerated Areas (EAs), otherwise referred to as clusters that were demarcated by the National Population Commission during the 2006 Housing and Population Census. The sampling frame of the survey included all the 774 local government areas in the 36 states of Nigeria and the Federal Capital Territory (FCT). A twostage sampling design was used to systematically select 100 households in each local government area from the primary sampling units (PSUs) for part A 
of the survey, and 50 households were systematically selected from each local government area in part B. Part A contained a welfare component while part $B$ elicited information on household consumption and expenditure. Altogether, 77400 households were enrolled for the study. The B component (the consumption approach) of the survey included 38700 households that were nationally representative.

There are two data requirements for the computation of unit values, but in the HNLSS only expenditure on tobacco consumption was reported. Therefore, the mean quantity consumed by households reported in the GATS conducted in 2012 was used. The GATS collected information on participants sociodemographics as well as a range of information regarding tobacco use, both smoked and smokeless, cessation, secondhand smoke etc. Detailed information regarding the data can be found elsewhere ${ }^{33}$.

\section{Theoretical framework}

In economics, the theory of demand relates the quantity of goods demanded to their prices. Following the work of Wilkins et al. ${ }^{34}$, the conventional tobacco consumption function can be expressed as:

$$
T C^{d}=f(P, \Pi, Y, T, L R)
$$

Equation 1 expresses tobacco consumption $\left(T C^{d}\right)$ as a function of the price of tobacco $(P)$, prices of other social goods, denoted by a price aggregator $(\Pi)$, total household income $(Y)$, household taste $\mathrm{T}$ (whether to smoke or not), and a vector of legislative restriction on tobacco use $(L R)$. Differentiating Equation 1 with respect to price $(P)$ will give the unit change in $T C^{d}$ due to change in price. Thus, the price elasticity of tobacco consumption is defined as:

$\eta=\left(\frac{\partial T C^{d}}{T C^{d}}\right) /\left(\frac{\partial P}{P}\right)$

\section{Empirical model}

Estimation of consumption function and price elasticity of tobacco demand

To estimate tobacco consumption function, a system of demand equation was specified. Also, the methodology proposed by Deaton ${ }^{35}$ was adopted to estimate the price elasticity of tobacco demand, given the crosssectional nature of the data used for the study. The Deaton methodology was adopted to leverage on 'spatial price variation' across clusters (or villages) in the absence of price data, to estimate the percentage change in quantity demanded with respect to changes in unit values across clusters. Deaton's methodology has two underlying assumptions. First, it assumes that there are constant within-cluster commodity prices. Second, there is variation in prices across clusters, referred to as variation in between-cluster prices. In effect, cluster means of commodity prices can be regressed against cluster means of quantities to estimate price elasticity of demand. However, given that household expenditure surveys conducted in most developing countries usually do not collect price data, the methodology requires that 'unit value' (the ratio of total/group expenditure $E_{i}$ and group quantity demanded) be used as proxy for the price of commodities. Following the work Chelwa and van Walbeek $^{25}$, two models are specified thus:

$\omega_{i c}=a_{1 i}+\varrho_{i} a+\beta_{1 i} \ln E_{i c}+\varphi_{1 i}\left(\ln E_{i c}\right)^{2}+\theta_{1} \sum_{J=1}^{N} \ln P_{c}+f_{c}+u_{1 i c}$

$\ln v_{i c}=a_{2 i}+\varrho_{i} a+\beta_{2 i} l_{n} E_{i c}+\theta_{2} \sum_{J=1}^{N} \ln P_{c}+u_{2 i c}$

The demand system depicted in Equation 3 is the tobacco consumption function (a Quadratic Almost Ideal Demand System) and $\omega_{i c}$ denotes the share of tobacco consumption expenditure in total household expenditure $E_{i c}$ of household i residing in cluster c. Equation 4 is the unit value equation and $\ln v_{i c}$ is the $\log$ of unit value. The terms, $\ln E_{i c}$ and $\left(\ln E_{i c}\right)^{2}$ are log of total household expenditure and the square of the log of household total expenditure (smokers only), respectively. The budget share and the unit value are functions of total household expenditure, a vector of household demographic characteristics (a) and the logarithm of $N$ price $\left(P_{c}\right)$. The term $f_{c}$ is the food price index, which captures variation across clusters and the same for households residing within the same cluster. In Equations 3 and $4, u_{1 i c}$ and $u_{2 i c}$ represent the stochastic error terms. The price $P_{c}$ is not observable but associated with unit value $\left(v_{i c}=\right.$ $\left.p_{t} t_{i c} / q_{i c}\right)$.

Equations 3 and 4 were estimated and the coefficient of log total household expenditure was employed to control for the effect of tobacco expenditure and household demographics on household budget share of tobacco consumption and the unit value. Afterwards, the mean of budget 
shares was computed. The unit values of smoking households residing in the same cluster is depicted thus:

$y_{c}^{\omega}=\frac{1}{n_{h}} \sum h \in c\left(\ln \omega_{i c}-\hat{\beta}_{1 i} \ln E-\varrho_{i} a\right)$

$y_{c}^{v}=\frac{1}{n_{h}} \sum h \in c\left(\ln v_{i c}-\hat{\beta}_{2 i} \ln E-\varrho_{i} a\right)$

Equations 5 and 6 give the quantities, $y_{c}^{\omega}$, and unit values, $y_{c}^{\circ}$, controlled for the effects of household expenditure and household demographics. Also, $n_{h}$ is the number of smoking households, which represent a subset of households in cluster $c$. The purging is done so as to correct for the effect of household income on budget share (demand) and unit values. This allowed this study to exploit unit values from tobacco consumption and thereby separate quality choice from exogenous price variations. In effect, $y_{c}^{w}$ was regressed on $y_{c}^{v}$ so that the coefficient obtained was denoted as $\varphi$. Finally, the following formula popularized by Deaton and used in the work of Chelwa and van Walbeek ${ }^{25}$ was adopted to derive the price elasticity of tobacco demand:

$\epsilon_{P}=\hat{\theta}_{1 i} / \underline{w}_{i}-\hat{\theta}_{2 i}$

Where $\underline{w}_{i}$ denotes the average total household tobacco expenditure, and $\hat{\theta}_{2 \mathrm{i}}$ and $\hat{\theta}_{1 \mathrm{i}}$, generated from Equations 3 and 4 , denote the coefficients of the unobserved price and are given by: $\hat{\theta}_{1 i}=\hat{\varphi} /(1+(\underline{w}-\hat{\varphi}) \zeta)$

$\hat{\theta}_{2 i}=1-\hat{\beta}_{1 i}\left(\underline{w}-\hat{\theta}_{1 i}\right) /\left(\hat{\beta}_{2 i}+\underline{w}\right)$

$\zeta=\hat{\beta}_{1 i} /\left(\hat{\beta}_{2 i}+\underline{w}\left(1-\hat{\beta}_{1 i}\right)\right.$

Where $\hat{\beta}_{1 i}$ and $\hat{\beta}_{2 i}$ are the coefficients of the budget share Equation 3 and unit value Equation 4, and $\varphi$ was the estimate generated when $y_{h c}^{w}$ was regressed on $y_{h c}^{v}$.

This methodological approach was criticized by Gibson and $\mathrm{Kim}^{30}$ on the grounds that it overestimates the price elasticity of tobacco demand as a result of failing to fully control for quality responses to increase in price. They instead proposed the use of an unrestricted model. However, the unrestricted model requires price data, not available in the HNLSS 2009-2010. As such, the Deaton model remains the most appropriate methodology for estimating price elasticity of tobacco products when analysing cross-sectional survey data, which usually do not include price data.

\section{RESULTS}

Table 1 shows the descriptive statistics of relevant variables in the data. The mean household size was $4.42 \pm 2.51$ and mean age of household head was $47.65 \pm 16.02$ years. Also, the average years of schooling/education was $9.75 \pm 3.83$ years. The mean food price index (FPI) was $1.03 \pm 0.19$. Household expenditure was reported in Nigerian Naira (N).

Table 1. Descriptive statistics of households, HNLSS 2009-2010, Nigeria

\begin{tabular}{|c|c|c|c|c|}
\hline Variable & Mean & SD & Vin & Vax \\
\hline Household size & 4.42 & 2.51 & 1 & 10 \\
\hline Age of household head (years) & 47.65 & 16.02 & 15 & 95 \\
\hline Education of household head (years) & 9.75 & 3.83 & 6 & 16 \\
\hline Food price index & 1.03 & 0.19 & 0.66 & 1.80 \\
\hline Household expenditure* (million & 1.90 & 9.19 & 0.0063 & 9700 \\
\hline Per capita expenditure* (million $\$$ ) & 0.497 & 23.60 & 0.0016 & 2900 \\
\hline Number of households & 34769 & & & \\
\hline Number of smoking households & 505 & & & \\
\hline Number of clusters & 91 & & & \\
\hline Mean number of households per cluster & 382 & & & \\
\hline Percentage of males in households & 84.78 & & & \\
\hline
\end{tabular}

*Exchange rate (2009-2010): Nigerian Naira 163 to US\$1, on average. HNLSS: Harmonized Nigerian Living Standard Survey. 
The average exchange rate at the time of the HNLSS 2009-2010 was 163 to $\$ 1$. Mean household yearly expenditure was $1.9 \pm 91.9$ million $¥$. Reported household expenditure showed a wide spread which is reflected in the reported range. There were 34769 households out of which 505 used tobacco. This presupposes that the prevalence of tobacco use was low among households. However, earlier studies reported much higher prevalence of tobacco use among households in Nigeria ${ }^{14,33}$. There were 91 clusters and the average number of households per cluster was 382 . The majority of the households $(84.78 \%)$ were headed by males.

Table 2 presents estimates from the tobacco consumption function and unit value models in Equations 3 and 4 . In the budget share regression, household size, location, household total expenditure and food price index were significant determinants of tobacco use in the full sample (all households with at least one individual who consumed tobacco). However, in rural and urban samples, only household expenditure and food price index were significant covariates. The coefficient of household expenditure is negative and statistically significant in all the samples (full, rural and urban). This may suggest that when income increases, the share of tobacco in household budgets declines, which does not necessarily mean a reduction in the consumption of tobacco. This result is similar to those of earlier studies. Pesko et al. ${ }^{29}$ estimated the price elasticity of tobacco products in India. Using unit value to proxy the prices of the various tobacco products consumed, they estimated the budget share of tobacco and showed that household expenditure was a significant covariate. However, the coefficient on the log of total household expenditure was positive showing that for tobacco using households, smoking increased as expenditure increased.

While this result is consistent with economic theory where for a normal good, quantity consumed

Table 2. Estimates of tobacco consumption function and unit value equation, Nigeria

\begin{tabular}{|c|c|c|c|}
\hline Variables & Full & Rural & Urban \\
\hline \multicolumn{4}{|c|}{ Budget share } \\
\hline$H_{\text {size }}$ & $-0.1450^{*}[0.0776]$ & -0.1309 [0.0799] & $-0.1279[0.1791]$ \\
\hline$H H_{a g e}$ & -0.1065 [0.1493] & $-0.1080[0.1437]$ & $-0.1716[0.4179]$ \\
\hline$H H_{\text {edu }}$ & $-0.0054[0.1069]$ & $-0.0776[0.1363]$ & $0.2983[0.1853]$ \\
\hline Urban & $-0.2544[0.1766]$ & & \\
\hline $\ln E$ & $-0.5252^{* * *}[0.0681]$ & $-0.5259^{* * *}[0.0655]$ & $-0.5655^{* *}[0.2118]$ \\
\hline Food price index & $-2.5887^{* * *}[0.6260]$ & $-2.2455^{* * *}[0.6365]$ & $-4.1160^{* * *}[0.9117]$ \\
\hline Constant & $2.8190^{* * *}[0.9154]$ & $2.8067^{* * *}[0.9458]$ & 3.1626 [2.5635] \\
\hline Number of households & 505 & 418 & 87 \\
\hline F-stat & $31.07^{* * *}$ & $30.11^{* *}$ & $6.05^{* * *}$ \\
\hline R-squared & 0.2962 & 0.2777 & 0.4046 \\
\hline \multicolumn{4}{|c|}{ Unit value } \\
\hline$H_{\text {size }}$ & $-0.1483^{*}[0.0793]$ & $-0.1337[0.0818]$ & $-0.1348[0.1823]$ \\
\hline$H H_{a g e}$ & $-0.1083[0.1540]$ & $-0.1098[0.1496]$ & $-0.1722[0.4224]$ \\
\hline$H H_{e d u}$ & $-0.0051[0.1092]$ & $-0.0782[0.1392]$ & $0.3022[0.1868]$ \\
\hline Urban & $-0.2638[0.1788]$ & & \\
\hline $\ln E$ & $0.4672^{* * *}[0.0685]$ & $0.4661^{* * *}[0.0660]$ & $0.4332^{*}[0.2129]$ \\
\hline Food price index & $-2.6610^{* * *}[0.6393]$ & $-2.3197^{* * *}[0.6527]$ & $-4.1755^{* * *}[0.9254]$ \\
\hline Constant & $-5.0236^{* * *}[0.9298]$ & $-5.0298^{* * *}[0.9652]$ & $-4.7697^{*}[2.5810]$ \\
\hline Number of households & 505 & 418 & 87 \\
\hline F-stat & $17.25^{* * *}$ & $28.28^{* * *}$ & $7.24^{* * *}$ \\
\hline R-squared & 0.1825 & 0.1599 & 0.351 \\
\hline
\end{tabular}

$H H$ represents household and sociodemographic variables such as age and education that are strictly that of household head. InE represents natural log of household expenditure. Figures in square brackets are the corresponding standard errors. Statistical significance: ${ }^{* *} 1 \%,{ }^{* *} 5 \%$ and ${ }^{*} 10 \%$ level. 
increases as income increases ceteris paribus, Chelwa and van Walbeek ${ }^{25}$ estimated the tobacco consumption function for Uganda and found household expenditure had a negative effect on tobacco spending/consumption. Since household expenditure remains the most preferred proxy for household income in economics literature, this result could also mean that households with lower income smoked more compared to higher income households. For instance, several studies have found that poor individuals/households are more likely to smoke compared to rich individuals/households. Palipudi et al. ${ }^{31}$ conducted a study on the impact of tobacco consumption on the poor in Bangladesh. Their study revealed that economically deprived persons/households were twice as likely to smoke compared to rich households.

Table 2 also shows that covariates such as age and level of education of household head were not significant in explaining tobacco use/consumption. The R-squared statistic for full, urban and rural samples $(0.2962,0.2777$ and 0.4046 , respectively) in this study showed that there are other factors that are not included in the model but associated with tobacco consumption in Nigeria. In the urban sample, only about $40 \%$ of the variation in smoking behaviour was explained by the covariates in the model. This is different from findings in the earlier studies conducted in developing countries ${ }^{30,32}$. These studies revealed that covariates such as household income/expenditure, household size, cluster level effects (prices and tastes/preferences) explain over $80 \%$ of tobacco consumption behaviour among smoking households ${ }^{30,32}$. Overall, this study revealed that household size, household total expenditure and food price index are significant predictors of tobacco consumption in Nigeria.

Other covariates not captured in the model (tobacco consumption function) that have been strongly linked with tobacco consumption are social factors such as peer pressure and smoker background (i.e. the influence of smoking behaviour of parents or close family members on children). For example, $\mathrm{WHO}^{33}$ carried out a study that investigated the impact of parenting behaviour on the onset of tobacco and alcohol use. A strong link between these two variables was found. However, the data used for the present study did not elicit information on respondents' background regarding parental tobacco use and this prevented the inclusion of this variable in the tobacco consumption function. Another possible cause of the low predictive power of the tobacco consumption model could be a result of the degree of variability exhibited in the data used for the study. In the statistical literature, the predictive power of models has been found to be impacted on by data sets that exhibit a high degree of variability ${ }^{34}$.

In the unit value regression, the covariates showed a similar pattern to the one revealed in the tobacco consumption model. Household size, household total expenditure and food price index were significant covariates in the model full sample. But in rural and urban sub-samples, household expenditure as well as food price index were the only significant variables. Deaton $^{35}$ found evidence that supports this finding. In that study, cross-sectional data for developing countries were analysed and results showed that household expenditure and cluster fixed effects are significantly associated with unit value.

Table 3 shows statistically significant conditional price elasticity of tobacco demand (the price elasticity of tobacco demand here was estimated for tobacco consuming households, i.e. conditional on the consumption of tobacco products) for full $(-0.62)$, rural $(-0.63)$ and urban $(-0.49)$ samples in Nigeria. This reveals that the demand for tobacco

Table 3. Conditional price elasticity of tobacco demand, Nigeria

$\begin{array}{lccc}\text { Statistic } & \text { Full } & \text { Rutral } & -0.4895^{* * *} \\ \hat{E}_{P} & -0.6247^{* * *} & -0.6331^{* * *} & {[0.0247]} \\ \text { Number of households } & {[0.0028]} & {[0.0035]} & (-0.5387,-0.4403) \\ & (-0.6301,-0.6192) & (-0.6401,-0.6262) & 818\end{array}$

The table gives price elasticity of tobacco demand (the effect of change in unit value/price on the quantity of tobacco demanded) with corresponding standard error in square brackets and 95\% confidence interval in parenthesis. These statistics are generated from bootstrap samples. Statistical significance: ${ }^{* * *} 1 \%$ level. 
is fairly price inelastic. The statistics, conditional price elasticity of tobacco demand and the standard errors (the standard errors for the bootstrap statistics were estimated using the standard deviation of the bootstrap distribution, 1000 replication of the bootstrap $)^{35}$ were generated from bootstrap samples. In classic economics, the estimated price elasticity means that for every increase in the price of tobacco, the quantity demanded falls but less than proportionate to the increase in price. For instance, these estimates show that for every, say $5 \%$ increase in the price of tobacco, there will be a corresponding reduction of about $3 \%$ in the quantity of tobacco demanded in the full and rural samples.

However, the corresponding reduction in the quantity of tobacco demanded in the urban sample (among smokers living in urban centres) will be about $2 \%$. In this case, the tobacco industry/ manufacturers are able to pass a substantial proportion of any increase in the excise tax of tobacco products to the consumers. This result is found to be supported by nearly all the studies on the price elasticity of tobacco products in developing countries and in some developed countries.

\section{DISCUSSION}

This study estimated the tobacco consumption function and revealed that household size, food price index, level of education/literacy of household head and income were significant determinants of tobacco consumption in Nigeria. Also, budget shares (QUAIDS) and unit value equations that allow for spatial variation in prices and quantities demanded were estimated to determine the price elasticity of tobacco demand in Nigeria.

A review of the taxation of tobacco products in developing countries conducted by Chaloupka et al. ${ }^{36}$ revealed that price elasticity of tobacco products had minimum and maximum values of -0.50 and -1.00. But the estimates from developed countries revealed higher values between -0.25 and -0.50 , indicating that higher income smokers are likely to be less responsive to increases in the prices compared to lower income smokers. In fact, many other studies have found that poorer smokers are more responsive to increases in the price of tobacco products. This also means that excise taxes on tobacco products is progressive.
Likewise, Eozenou and Fishburn ${ }^{24}$ estimated the price elasticity of cigarette demand in Vietnam and found it to be centered around -0.53. In the Pesko et al. ${ }^{29}$ and Chelwa and van Walbeek ${ }^{25}$ studies cited earlier, they found that the own-price elasticity of tobacco products ranged from -0.40 to -0.90 , and -0.26 to -0.41 , respectively. In India, Guindon et al. ${ }^{26}$ carried out a study that aimed at estimating the impact of tobacco taxes on different socioeconomic groups. They found that smoking households in low socioeconomic strata respond more to price changes compared with households in other strata. Another study conducted by Selvaraj et al. ${ }^{23}$ on the price elasticity of tobacco products in India revealed that poorer consumers appear to be more responsive to price changes. They reported that the own price elasticity of bidi (a tobacco product popular in India) was the highest among poorer households at -0.43 .

\section{Limitations}

This study has some limitations, which were mainly as a result of limited data. The price elasticity for the different types of tobacco products was not estimated since this was not elicited in the data. Also, the HNLSS involves household level data and as such important sociodemographics variables such as age, level of education and sex in the data set were strictly that of the household head. Consequently, this study may not have been able to capture the effect of these variables at individual level. Finally, as noted by Gibson and $\mathrm{Kim}^{30}$, it is not unlikely that the price elasticity of tobacco demand reported in this study overestimated the actual response of tobacco demand to price increase.

\section{CONCLUSIONS}

Our results showed that the price elasticity of tobacco demand was -0.63 and -0.49 , for rural and urban samples, respectively, while the national value was -0.62 . The implication is that for every $5 \%$ increase in the price of tobacco, there will be a corresponding reduction of about $3 \%$ in the quantity of tobacco demanded in the national and rural samples. While the same increase in the price of tobacco products will generate about $2 \%$ reduction in quantity of tobacco consumed in urban settings in Nigeria. In simple economic terminology, the demand for tobacco products in Nigeria is fairly price inelastic. 


\section{REFERENCES}

1. Hall W. What has research over the past two decades revealed about the adverse health effects of recreational cannabis use? Addiction. 2015;110(1):19-35. doi:10.1111/add.12703

2. Courtney R. The Health Consequences of Smoking-50 Years of Progress: A Report of the Surgeon General, 2014. Drug Alcohol Rev. 2015;34(6):694-695. doi:10.1111/dar.12309

3. Kanavos P. The rising burden of cancer in the developing world. Ann Oncol. 2006;17(Suppl 8):viii15-viii23. doi:10.1093/annonc/mdl983

4. Samet JM. Tobacco smoking: the leading cause of preventable disease worldwide. Thorac Surg Clin. 2013;23(2):103-112. doi:10.1016/j.thorsurg.2013.01.009

5. World Health Organization. WHO report on the global tobacco epidemic: the MPOWER package. Geneva, Switzerland: World Health Organization: 2008. https:// www.who.int/tobacco/mpower/mpower_report_ full_2008.pdf. Accessed February 16, 2019.

6. Mannino DM, Braman S. The epidemiology and economics of chronic obstructive pulmonary disease. Proc Am Thorac Soc. 2007;4(7):502-506. doi:10.1513/pats.200701-001fm

7. Bartal M. Health effects of tobacco use and exposure. Monaldi Arch Chest Dis. 2001;56(6):545-554. PMID:11980288.

8. Green NS, Damus K, Simpson JL, et al. Research agenda for preterm birth: recommendations from the March of Dimes. Am J Obstet Gynecol. 2005;193(3):626-635. doi:10.1016/j.ajog.2005.02.106

9. Iams JD, Romero R, Culhane JF, Goldenberg RL. Primary, secondary, and tertiary interventions to reduce the morbidity and mortality of preterm birth. Lancet. 2008;371(9607):164175. doi:10.1016/S0140-6736(08)60108-7

10. Hillis SD, Anda RF, Dube SR, Felitti VJ, Marchbanks PA, Marks JS. The association between adverse childhood experiences and adolescent pregnancy, long-term psychosocial consequences, and fetal death. Pediatrics. 2004;113(2):320-327. doi:10.1542/peds.113.2.320

11. Kaiser L, Allen LH. Position of the American Dietetic Association: nutrition and lifestyle for a healthy pregnancy outcome. J Am Diet Assoc. 2008;108(3):553561. doi:10.1016/j.jada.2008.01.030

12. World Health Organization. Curbing the epidemic: governments and the economics of tobacco control. Tob Control. 1999;8(2):196-201. doi:10.1136/tc.8.2.196

13. Ng M, Freeman MK, Fleming TD, et al. Smoking prevalence and cigarette consumption in 187 countries, 1980-2012. JAMA. 2014;311(2):183-192. doi:10.1001/jama.2013.284692

14. World Health Organization.Tobacco: Key facts. Geneva, Switzerland: World Health Organization; 2019. https:// www.who.int/news-room/fact-sheets/detail/tobacco. Accessed June 24, 2019.
15. Mathers CD, Loncar D. Projections of global mortality and burden of disease from 2002 to 2030. PLoS Medicine. 2006;3(11):e442. doi:10.1371/journal.pmed.0030442

16. The World Bank. Data: Global Consumption Database. http://datatopics.worldbank.org/consumption/. Accessed Aug 23, 2019.

17. The Tobacco Atlas. Nigeria. https://tobaccoatlas.org/ country/nigeria/. Accessed August 23, 2019.

18. World Health Organization. Noncommunicable diseases: Country profiles, 2014. Geneva, Switzerland: World Health Organization; 2014. https://apps.who.int/iris/ bitstream/handle/10665/128038/9789241507509_eng. pdf; jsessionid=84D405E43D627 A 1 15D 75E9 B9012BC204?sequence=1. Accessed August 24, 2019.

19. Yach D. The origins, development, effects, and future of the WHO Framework Convention on Tobacco Control: a personal perspective. Lancet. 2014;383(9930):17711779. doi:10.1016/S0140-6736(13)62155-8

20. World Health Organization. History of the World Health Organization framework convention on tobacco control. Geneva, Switzerland: World Health Organization; 2009. https://apps.who.int/iris/bitstream/ handle/10665/44244/9789241563925_eng.pdf. Accessed August 24, 2019.

21. Pierce JP, White VM, Emery SL. What public health strategies are needed to reduce smoking initiation? Tob Control. 2012;21(2):258-264. doi:10.1136/tobaccocontrol-2011-050359

22. Czubek M, Johal S. Econometric analysis of cigarette consumption in the UK. London, UK: HM Revenue \& Customs; 2010. http://citeseerx.ist.psu.edu/viewdoc/ download?doi=10.1.1.307.8455\&rep=rep1\&type=pdf. Accessed August 24, 2019.

23. Selvaraj S, Srivastava S, Karan A. Price elasticity of tobacco products among economic classes in India, 2011-2012. BMJ Open. 2015;5(12):e008180. doi:10.1136/bmjopen-2015-008180

24. Eozenou P, Fishburn B. Price Elasticity Estimates of Cigarette Demand in Vietnam. Florence, Italy and Geneva, Switzerland: European University Institute, World Health Organization; 2001. https://mpra.ub.uni-muenchen. de/12779/1/MPRA_paper_12779.pdf. Accessed August $24,2019$.

25. Chelwa G, van Walbeek C. Does cigarette demand respond to price increases in Uganda? Price elasticity estimates using the Uganda National Panel Survey and Deaton's method. BMJ Open. 2019;9(3):e026150. doi:10.1136/bmjopen-2018-026150

26. Guindon GE, Nandi A, Chaloupka IVFJ, Jha P. Socioeconomic differences in the impact of smoking tobacco and alcohol prices on smoking in India. Cambridge, MA: National Bureau of Economic Research; 2011. doi:10.3386/w17580

27. Martinez E, Mejia R, Perez-Stable E. An empirical analysis of cigarette demand in Argentina. Tob Control. 2015;24(1):89- 
93. doi:10.1136/tobaccocontrol-2012-050711

28. Guindon E, Paraje G, Chaloupka F. The Impact of Prices and Taxes on the Use of Tobacco Products in Latin America and the Caribbean. AM J Public Heal. 2018;108(Suppl 6):S492-S502. doi:10.2105/ajph.2014.302396r

29. Pesko MF, Tauras JA, Huang J, Chaloupka FJ. The influence of geography and measurement in estimating cigarette price responsiveness. In: NBER Working Papers 22296. Cambrigde, MA: National Bureau of Economic Research; 2016. doi:10.3386/w22296

30. Gibson J, Kim B. The price elasticity of quantity, and of quality, for tobacco products. Health Econ. 2019;28(4):587-593. doi:10.1002/hec.3857

31. Palipudi KM, Gupta PC, Sinha DN, Andes LJ, Asma S, McAfee T. Social Determinants of Health and Tobacco Use in Thirteen Low and Middle Income Countries: Evidence from Global Adult Tobacco Survey. PLoS One. 2012;7(3):e33466. doi:10.1371/journal.pone.0033466

32. United Nations. UN Comtrade Database: Data Visualization. https://comtrade.un.org/. Accessed August $24,2019$.

33. World Health Organization, Centers for Disease Control and Prevention. Global Adult Tobacco Survey: Nigeria Fact Sheet, 2012. https://www.tobaccofreekids.org/ assets/global/pdfs/en/GATS_Nigeria_Fact_Sheet_2012. pdf. Accessed August 24, 2019.

34. World Bank. Economic analysis of tobacco demand: Tool 3, Demand Analysis. 2004;80576. http://siteresources. worldbank.org/INTPH/Resources/3Demand.pdf. Accessed August 24, 2019.

35. Deaton A. The analysis of household surveys: a microeconometric approach to development policy. World Bank; 1997. doi:10.1596/0-8018-5254-4

36. Chaloupka FJ, Yurekli A, Fong GT. Tobacco taxes as a tobacco control strategy. Tob Control. 2012;21(2):172180. doi:10.1136/tobaccocontrol-2011-050417
CONFLICTS OF INTEREST

The author has completed and submitted the ICMJE Form for Disclosure of Potential Conflicts of Interest and none was reported.

FUNDING

There was no source of funding for this research.

PROVENANCE AND PEER REVIEW

Not commissioned; externally peer reviewed. 